\title{
The effect of fructan-enriched diet on bone turnover parameters in ovariectomized rats under calcium restriction
}

\author{
Kinga Topolska ${ }^{1, A-B, D, F} \oplus$, Marek Bieńko ${ }^{2, B, F} \oplus$, Agnieszka Filipiak-Florkiewicz ${ }^{1, B-C, F \oplus}$, \\ Radosław Piotr Radzki ${ }^{2, B, F}$, Ewa Cieślik ${ }^{1, E-F \oplus}$ \\ ${ }^{1}$ Department of Nutrition Technology and Consumption, Faculty of Food Technology, University of Agriculture, Krakow, \\ Poland \\ 2 Department of Animal Physiology, Faculty of Veterinary Medicine, University of Life Sciences, Lublin, Poland \\ A - Research concept and design, B - Collection and/or assembly of data, C - Data analysis and interpretation, \\ $D$ - Writing the article, $E$ - Critical revision of the article, $F$ - Final approval of article
}

Topolska K, Bieńko M, Filipiak-Florkiewicz A, Radzki RP, Cieślik E. The effect of fructan-enriched diet on bone turnover parameters in ovariectomized rats under calcium restriction. Ann Agric Environ Med. 2020; 27(2): 219-224. doi: 10.26444/aaem/108658

\begin{abstract}
Introduction. Osteoporosis, the "quiet epidemic", is one of the most serious threats to public health. It is known that estrogen plays a significant role in the regulation of bone turnover, and its loss at menopause causes osteoporosis. Added to this, insufficient calcium intake accelerates bone mass loss, increasing the risk of fractures.

Objective. The study aimed to answer the question whether a fructan-enriched diet could be helpful in preventing from disturbances in bone turnover caused by calcium restriction combined with ovariectomy-induced estrogen deficiency. The differences related to the kind of fructan and "matrix effect" of fructan action (form of addition) were also evaluated.

Materials and method. The study was conducted using sham-operated (control groups) or ovariectomized (OVX) rats fed a calcium restricted diet. The treatment diets contained one of three fructan sources - Jerusalem artichoke, yacon and Beneo Orafti Synergy 1 - added alone or as an ingredient of strawberry sorbet, all in the amount providing $8 \%$ fructans. Analyses of biological material included: serum $\mathrm{Ca}, \mathrm{Mg}$ and $\mathrm{P}$ concentrations, alkaline phosphatase activity (ALP), osteocalcin (OC) and C-telopeptide degradation products from type I collagen (CTX). Densitometric parameters of femora were also assayed. Results. Among markers of bone turnover, the ALP activity depended both on the kind of fructan and the form of addition. The highest value was shown in the OVX group fed a low-calcium diet, whereas administration of diet enriched with Jerusalem artichoke led to an almost 50\% decrease in the value of this parameter. Dietary fructans also lowered the OC level. Feeding rats with diet containing sorbet enriched in yacon or Jerusalem artichoke resulted in a decrease of CTX, compared to the diet containing yacon alone or fructan formulation in both forms No significant differences were observed in densitometric parameters between treatment groups.

Conclusions. The obtained findings suggest that fructan administration with a calcium-restricted diet might exert a positive effect on bone turnover parameters. Regarding the form of their addition, it is possible that other constituents of sorbets contributed to the fructan action. It remains open whether this impact would be significant over a longer period of time.
\end{abstract}

Key words

fructans, calcium dietary restriction, bone turnover, densitometry, ovariectomy

\section{INTRODUCTION}

The skeleton provides mechanical support for stature and locomotion, protects vital organs, controls homeostasis of minerals and must be maintained by constant bone modeling to carry out these important functions throughout life [1]. The loss of bone an its lowered quality is the hallmark of osteoporotic bone [2]. Osteoporosis, also called the "silent disease" or "quiet epidemic", is one of the most serious threats to public health, and is the cause of more than 8.9 million fractures a year worldwide $[3,4,5,6]$. It is known that estrogen plays a significant role in maintaining bone homeostasis and regulating its remodeling. A deficiency of this hormone is observed after menopause [7], added to which insufficient calcium intake accelerates loss of bone mass and increases the risk for osteoporotic fractures, especially in women after

Address for correspondence: Kinga Topolska, Department of Nutrition Technology and Consumption, Faculty of Food Technology, University of Agriculture in Kraków, Poland

E-mail: kinga.topolska@urk.edu.pl

Received: 12.01.2019; accepted: 12.04.2019; first published: 25.04.2019 menopause [5]. Despite substantial evidence that calcium consumption is critical for optimal bone health and reducing later fracture risk, people do not consume adequate amounts of calcium. According to Price et al. [8], the average dietary calcium intake is still below the recommended amounts, both for teenage girls and post-menopausal women. Because of the fact that the prevalence of osteoporosis is a very serious health problem, many scientists are concerned about the methods for treatment of this disease, including the usage of specific drugs. Although these anti-osteoporotic drugs can be used to improve the mineral density of bone and reduce the fracture risk, evidences suggests that their longterm use may have adverse effects on the human organism [9]. This is why it is crucial to develop alternative bone protective agents, in this respect, natural products from plants could be a good example [4]. Increasing interest in functional foods has driven research into the prevention and treatment of several chronic diseases [10]. Among functional bioactive compounds, fructans attract special attention. These prebiotics occur naturally in chicory root, artichoke, wheat, onion, asparagus, agave, and banana [11]. Fructans 
are characterized by hypoglycaemic and hypolipidaemic properties, as well as exerting the potential to enhance mineral bioavailability $[12,13]$. Their effects on calcium absorption and bone mineral density have been reviewed [10, $14,15]$. The properties of these polysaccharides are depended on their structure, including the degree of polymerization. Some previous studies concerned several inulin-fructan sources, have shown that the chemical composition and action varies markedly $[16,17,18,19,20]$. Some evidence also shows the antioxidative action of fructan and a link between nutrients, antioxidant intake and bone health [21].

The choice of a proper experimental model is crucial for studies concerning the potential functional properties of food products. The ovariectomized (OVX) rat model is the approved preclinical model for studying how the decline in the endogenous production of estrogen by the ovaries leads to postmenopausal osteoporosis, and how potential interventions can preserve bone condition in this period of life [22]. The ovariectomy approach to generate postmenopausal osteoporotic animal models was applied in rodents, mainly in rats $[2,23$, 24]. This is why ovariectomized rats were used in the present study regarding the anti-osteoporotic potential of fructans from different sources. In the knowledge that antioxidants could play an important role in the protection of bone quality, for the current study it was decided to verify the fructan action in a strawberry matrix, which is a rich source of many bioactive compounds, especially polyphenols. On this basis, it was hypothesized that not only origin but also the food matrix could effectively modulate fructan action. To the best of the authors' knowledge, this is the first paper presenting the effect of feeding ovariectomized rats with a diet enriched in fructans from three different sources, added in two different forms - alone (as raw materials) or as components of a food product.

\section{MATERIALS AND METHOD}

Research materials. Research material were the pulp from tubers of Jerusalem artichoke (Helianthus tuberosus L.) var. Albik (agricultural holding using sustainable system of plant production, Wielkopolska Region, Poland), yacon (Smallanthus sonchifoulis) root powder (Oxapampa, Peru - EverTrust, United Kingdom) and Beneo Orafti Synergy 1 (Belgium) used as the ingredients of strawberry sorbets. For the sorbet production, strawberries (Fragaria $\times$ ananassa Duchesne) var. Senga Sengana (Oerlemans Foods, Poland) were used. The sorbets were prepared according to [16]. These products contained calcium in the amount $7.82 \mathrm{mg} / 100 \mathrm{~g}$ - sorbet enriched in Jerusalem artichoke, $15.09 \mathrm{mg} / 100 \mathrm{~g}$ - sorbet enriched in yacon root powder, and $4.05 \mathrm{mg} / 100 \mathrm{~g}$ - sorbet enriched in Beneo Orafti Synergy 1, respectively.

Study design and intervention. The study involved animal subjects, during which ethical standards and all applicable institutional and/or national guidelines for the care and use of animals were followed. Experimental animals were 12 -week-old female Wistar rats, with a mean body weight of $269.4 \pm 31.4 \mathrm{~g}$. They were kept in an animal house, in a controlled environment: under a 12/12-h light-dark cycle, at a constant temperature of $22 \pm 2^{\circ} \mathrm{C}$ and humidity of $55 \pm 2 \%$. The rats were housed in Tecniplast plastic cages (Eurostandard Type IV 1354G; three animals/cage).

After seven days of acclimatization, the animals were randomly divided and submitted to either a sham operation (SHO) or bilateral ovariectomy (OVX). During the sham operation, ovaries were bilaterally isolated from the approach in the medial line and replaced intact. During ovariectomy, ovaries were removed bilaterally from the approach in the medial line. Special care was taken to prevent accidental reimplantation of ovarian tissue during surgery. Uterine atrophy (observed during dissection) indicated a properly made ovariectomy. After four days of convalescence, the rats $(n=72)$ were randomly selected and assigned to validation (three groups, with $\mathrm{n}=8$ /group) or treatment groups (six groups ( $n=8 /$ group). All animals were fed diets prepared according to AIN 93M diet [25], (including mineral as well as vitamin mixes), with some modifications (Tab. 1):

- in validation model; group I (SHO-RC): sham-operated rats fed modified AIN-93M diet with recommended calcium dose - 5,000 mg/kg diet, group II (SHO-LC): sham-

Table 1. Experimental diets - ingredients and energy value

\begin{tabular}{|c|c|c|c|c|c|c|c|c|}
\hline \multirow[b]{2}{*}{ Dietary ingredient (g/kg) } & \multicolumn{8}{|c|}{ Group } \\
\hline & SHO-RC & $\begin{array}{l}\text { SHO-LC } \\
\text { OVX-LC }\end{array}$ & OVX-LC-JA & OVX-LC-Y & OVX-LC-F & OVX-LC-JAS & OVX-LC-YS & OVX-LC-FS \\
\hline cellulose & 50.00 & 50.00 & 31.50 & 28.07 & 50.00 & 23.05 & 19.32 & 43.21 \\
\hline sucrose & 100.00 & 100.00 & 77.17 & 10.63 & 91.61 & 0.00 & 0.00 & 0.00 \\
\hline mineral mix $†$ & 35.00 & 35.00 & 35.00 & 35.00 & 35.00 & 35.00 & 35.00 & 35.00 \\
\hline Jerusalem artichoke & - & - & 144.93 & - & - & - & - & - \\
\hline yacon & - & - & - & 211.64 & - & - & - & - \\
\hline Beneo Orafti Synergy 1 & - & - & - & - & 89.83 & - & - & - \\
\hline sorbet with Jerusalem artichoke & - & - & - & - & - & 470.30 & - & - \\
\hline sorbet with yacon & - & - & - & - & - & - & 524.11 & - \\
\hline sorbet with Beneo Orafti Synergy1 & - & - & - & - & - & - & - & 511.22 \\
\hline energy value [kcal/g diet] & 3.80 & 3.80 & 3.50 & 3.49 & 3.48 & 3.48 & 3.45 & 3.44 \\
\hline
\end{tabular}

SHO-RC - diet with recommended calcium dose, Ca content: $5,000 \mathrm{mg} / \mathrm{kg}$ diet; LC - calcium deficient diets ( $60 \%$ recommended Ca dose, Ca content: $3,000 \pm 0.1 \mathrm{mg} / \mathrm{kg}$ diet), i.e. SHO-LC and OVXLC: low-calcium diet; OVX- LC-JA: low-calcium diet enriched with Jerusalem artichoke; OVX-LC-Y: low-calcium diet enriched with yacon; OVX-LC-F: low-calcium diet enriched with Beneo Orafti Synergy 1; OVX-LC-JAS: low-calcium diet enriched with sorbet containing Jerusalem artichoke; OVX-LC-YS: low-calcium diet enriched with sorbet containing yacon; OVX-LC-FS: low-calcium diet enriched with sorbet containing Beneo Orafti Synergy 1.

tin LC groups corn starch was placed in mineral mix instead of calcium

The remaining ingredients ( $\mathrm{g} / \mathrm{kg}$ diet) were: casein 140.00; soybean oil 40.00; vitamin mix 10.00; choline bitartate 2.5; L-cystine 1.80 and tert-butylhydroquinone 0.008 . 
operated rats fed a low calcium (40\% of Ca deficiency) diet, group III (OVX-LC) - ovariectomized rats fed a low calcium ( $40 \%$ of Ca deficiency) diet;

- in treatment groups; animals were fed a low-calcium diet with one of three fructan-enriched sources added:

(A) alone as raw materials: group IV (OVX-LC-F): with the formulation Beneo Orafti Synergy 1; group V (OVXLC-Y): with yacon root powder; group VI (OVX-LC-JA): with Jerusalem artichoke pulp; (B) a component of sorbets: groups VII, VIII and IX (OVX-LC-FS, OVX-LC-YS, OVXLC-JAS, respectively).

Amount of fructans in diets of animals in groups IVIX - 8\%; calcium content in low-calcium diets (for groups II-IX) was on the level of $3,000 \pm 0.1 \mathrm{mg} / \mathrm{kg}$ diet. Jerusalem artichoke pulp, as well as all sorbets, were added to the diet after lyophilization (Christ Alpha 1-4 apparatus, Germany).

All rats were allowed free access to deionized water throughout the whole experiment. The SHO-RC group was fed the diet ad libitum, and the other groups obtained the same amount of diet to avoid the hypertrophy induced by ovariectomy. Weight gain was monitored once a week.

At the end of the experiment, rats were euthanized, according to the ethical guidelines for animal experimentation. All the procedures were approved by the First Local Ethical Committee on Animal Testing at the Jagiellonian University in Kraków (No. 119/2011).

\section{Analyses of rat serum and femur}

Serum parameters. Serum ionized calcium (calculated on the basis on total calcium level determination), magnesium and phosphorus concentration, as well as alkaline phosphatase activity, were quantified using a BS 120 Analyzer (Shenzhen MindrayBio-Medical Electronics Co., Ltd., Stamar, Polandauthorized distributor). The serum level of osteocalcin was estimated using a Rat-Mid ${ }^{\mathrm{TM}}$ OsteocalcinEIA Kit (Immunodiagnostic Systems), and C-telopeptide degradation products from type I collagen (CTX) was determined by RatLaps $^{\text {TM }}$ EIA (Immunodiagnostic Systems).

Bone densitometry. Bone mineral density (BMD) and bone mineral content (BMC) of isolated femora were established by a Norland Excell Plus Densitometer (Fort Atkinson, WI, USA) equipped with Illuminatus DXA Software v.4.5 with a Small Animal Scan option. The measurements were performed using the following parameters: scout scan speed $100 \mathrm{~mm} / \mathrm{s}$, resolution $3.0 \times 3.0 \mathrm{~mm}$; measurement scan speed $10 \mathrm{~mm} / \mathrm{s}$, resolution $1.0 \times 1.0 \mathrm{~mm}$. The region of interest (ROI) after scout scan was defined manually. Densitometer was calibrated using the quality assurance phantoms (QA-Phantom), provided by the manufacturer, and performed in agreement with set procedures before every measurement series.
Statistical analysis. Data were presented as mean value \pm standard deviation (SD). All the calculations were performed with statistical software package Statistica 9.1 (StatSoft Inc., USA). Hypothesis about normal distribution was verified by Shapiro-Wilk test, and homogeneity of variance by Levene'a test. Differences between SHO-RC and SHO-LC groups, as well as between SHO-LC and OVX-LC, were analyzed by the Student's t-test.

The data concerning treatment groups were subjected to two-factorial $(3 \times 2)$ analysis of variance, including three kinds of fructan sources and two forms of their addition to the diet. The differences between the means were evaluated using the post-hoc NIR Fisher test; significance level $\mathrm{p} \leq 0.05$

\section{RESULTS}

Validation model. The serum concentrations of biochemical parameters, as well as BMD and BMC for the groups SHORC, SHO-LC and OVX-LC, the validation model, are shown in Table 2.

With regard to the effect of dietary calcium restriction in the sham-operated groups, a significant decrease was observed in the level of ionized calcium. In the case of phosphorus, it was maintained in the same direction of change, with a dramatic reduction by ca. $30 \%$. Simultaneously, the concentration of magnesium remained unchanged. The analysis of bone turnover parameter showed a significant decrease in alkaline phosphatase (from 129.59 to 93.28) between the SHO-RC and SHO-LC groups. On the contrary, calcium hypoalimentation did not affect osteocalcin concentration in rat serum. Eight weeks of calcium hypoalimentation also did not cause significant differences between sham-operated groups in the values of densitometric parameters, i.e. bone mineral content, bone mineral density and bone area.

In turn, calcium hypoalimentation in the ovariectomized rats led to significant changes in the levels of examined biochemical parameters related to bone metabolism, except for serum concentrations of magnesium, phosphorus and alkaline phosphatase. The ionized calcium level was lower $(\mathrm{p} \leq 0.05)$ in OVX-LC group than in SHO-LC animals. Moreover, OVX-LC rats were characterized by a more than two-fold enhancement in osteocalcin concentration, and also a $75 \%$ increase in CTX level in the serum.

Effect of fructan-enriched diet. Table 3 presents the resulting changes in the studied parameters after the addition of fructans to the rat diet. The fructan-enriched diets did not affect the serum concentrations of ionized calcium (except for LC-F group) and magnesium. There was a significant increase in the phosphorus level in LC-FS animals, compared to the

Table 2. Levels of serum parameters of bone turnover and densitometric parameters of femur; results concerned the validation model

\begin{tabular}{|c|c|c|c|c|c|c|c|c|c|c|c|c|c|c|c|c|}
\hline \multirow{2}{*}{ Group } & \multicolumn{2}{|c|}{$\mathrm{Ca}^{2+}(\mathrm{mg} / \mathrm{dl})$} & \multicolumn{2}{|c|}{$\mathrm{Mg}(\mathrm{mg} / \mathrm{dl})$} & \multicolumn{2}{|c|}{$P(\mathrm{mg} / \mathrm{dl})$} & \multicolumn{2}{|c|}{$\mathrm{ALP}(\mathrm{mg} / \mathrm{dl})$} & \multicolumn{2}{|c|}{$\mathrm{OC}(\mathrm{ng} / \mathrm{ml})$} & \multicolumn{2}{|c|}{ CTX (ng/ml) } & \multicolumn{2}{|c|}{$\mathrm{BMC}(\mathrm{g})$} & \multicolumn{2}{|c|}{$\mathrm{BMD}\left(\mathrm{g} / \mathrm{cm}^{2}\right)$} \\
\hline & Mean & SD & Mean & SD & Mean & SD & Mean & SD & Mean & SD & Mean & SD & Mean & SD & Mean & SD \\
\hline SHO-RC & $5.92^{\mathrm{b}}$ & 0.32 & $2.85^{\mathrm{a}}$ & 0.44 & $7.25^{\mathrm{b}}$ & 1.80 & $129.59^{b}$ & 27.12 & $167.37^{\mathrm{a}}$ & 45.62 & $13.26^{b}$ & 2.44 & $0.38^{\mathrm{a}}$ & 0.03 & $0.12^{\mathrm{a}}$ & 0.00 \\
\hline OVX-LC & $5.16^{\mathrm{A}}$ & 0.22 & $2.83^{\mathrm{A}}$ & 0.23 & $5.65^{\mathrm{A}}$ & 0.60 & $104.93^{A}$ & 22.4 & $297.61^{\text {B }}$ & 94.75 & $16.84^{\mathrm{B}}$ & 3.18 & $0.38^{A}$ & 0.02 & $0.11^{\mathrm{A}}$ & 0.00 \\
\hline
\end{tabular}

SHO-RC - diet with recommended calcium dose; SHO-LC and OVX-LC - low-calcium diet; ALP - alkaline phosphatase; OC - osteocalcin; CTX - C-telopeptide degradation products from type I collagen); BMC - bone mineral content); BMD - bone mineral density. 
Table 3. Levels of serum parameters of bone turnover and densitometric parameters of femur; results concerned the treatment groups

\begin{tabular}{|c|c|c|c|c|c|c|c|c|c|c|c|c|c|c|c|c|}
\hline \multirow{2}{*}{ Group } & \multicolumn{2}{|c|}{$\mathrm{Ca}^{2+}(\mathrm{mg} / \mathrm{dl})$} & \multicolumn{2}{|c|}{$\mathrm{Mg}(\mathrm{mg} / \mathrm{dl})$} & \multicolumn{2}{|c|}{$P(\mathrm{mg} / \mathrm{dl})$} & \multicolumn{2}{|c|}{$\operatorname{ALP}(\mathrm{mg} / \mathrm{dl})$} & \multicolumn{2}{|c|}{$\mathrm{OC}(\mathrm{ng} / \mathrm{ml})$} & \multicolumn{2}{|c|}{$\mathrm{CTX}$ (ng/ml) } & \multicolumn{2}{|c|}{$\mathrm{BMC}(\mathrm{g})$} & \multicolumn{2}{|c|}{$\mathrm{BMD}\left(\mathrm{g} / \mathrm{cm}^{2}\right)$} \\
\hline & Mean & SD & Mean & SD & Mean & SD & Mean & SD & Mean & SD & Mean & SD & Mean & SD & Mean & SD \\
\hline OVX-LC & $5.16^{\mathrm{b}}$ & 0.22 & $2.83^{\mathrm{a}}$ & 0.23 & $5.65^{\mathrm{a}}$ & 0.60 & $104.93^{c}$ & 22.40 & $297.61^{\mathrm{b}}$ & 94.75 & $16.84^{\mathrm{ab}}$ & 3.18 & $0.38^{\mathrm{a}}$ & 0.02 & $0.11^{\mathrm{a}}$ & 0.00 \\
\hline OVX-LC-Y & $5.15^{\mathrm{b}}$ & 0.23 & $2.62^{\mathrm{a}}$ & 0.22 & $6.31^{\mathrm{a}}$ & 1.42 & $84.88^{\mathrm{b}}$ & 24.88 & $257.25^{\mathrm{ab}}$ & 27.21 & $18.97^{\mathrm{b}}$ & 4.71 & $0.37^{a}$ & 0.03 & $0.11^{\mathrm{a}}$ & 0.01 \\
\hline OVX-LC-JA & $5.15^{\mathrm{b}}$ & 0.15 & $2.65^{\mathrm{a}}$ & 0.20 & $5.72^{\mathrm{a}}$ & 0.62 & $77.13^{\mathrm{ab}}$ & 19.91 & $250.63^{\mathrm{ab}}$ & 63.60 & $17.21^{\mathrm{ab}}$ & 3.80 & $0.37^{\mathrm{a}}$ & 0.04 & $0.11^{\mathrm{a}}$ & 0.01 \\
\hline OVX-LC-FS & $5.33^{\mathrm{b}}$ & 0.14 & $2.87^{\mathrm{a}}$ & 0.27 & $7.25^{c}$ & 1.10 & $65.53^{a}$ & 7.41 & $218.69^{a}$ & 77.97 & $20.24^{\mathrm{b}}$ & 3.72 & $0.39^{a}$ & 0.06 & $0.12^{\mathrm{a}}$ & 0.01 \\
\hline OVX-LC-YS & $5.28^{\mathrm{b}}$ & 0.10 & $2.77^{a}$ & 0.13 & $6.60^{\mathrm{b}}$ & 0.71 & $66.21^{\mathrm{a}}$ & 11.30 & $208.69^{a}$ & 41.95 & $14.12^{\mathrm{a}}$ & 2.09 & $0.36^{a}$ & 0.03 & $0.11^{\mathrm{a}}$ & 0.01 \\
\hline OVX-LC-JAS & $5.26^{\mathrm{b}}$ & 0.20 & $2.77^{\mathrm{a}}$ & 0.26 & $6.18^{\mathrm{a}}$ & 0.62 & $55.08^{\mathrm{a}}$ & 11.22 & $246.98^{\mathrm{ab}}$ & 42.22 & $14.75^{\mathrm{a}}$ & 3.27 & $0.38^{\mathrm{a}}$ & 0.03 & $0.11^{\mathrm{a}}$ & 0.01 \\
\hline
\end{tabular}

OVX-LC - low-calcium diet; OVX-LC-F - low-calcium diet enriched with Beneo Orafti Synergy 1; OVX-LC-Y - low-calcium diet enriched with yacon; OVX- LC-JA - low-calcium diet enriched with Jerusalem artichoke; OVX-LC-FS - low-calcium diet enriched with sorbet containing Beneo Orafti Synergy 1; OVX-LC-YS - low-calcium diet enriched with sorbet containing yacon; OVX-LC-JAS low-calcium diet enriched with sorbet containing Jerusalem artichoke; ALP - alkaline phosphatase; OC - osteocalcin;

$a, b$ - different letters mean significant differences among groups $(p \leq 0.05)$

CTX - C-telopeptide degradation products from type I collagen; BMC - bone mineral content; BMD - bone mineral density.

LC control group, as well as in rats fed with diets enriched in fructans added alone (independently of their source) and in the OVX-LC-JAS group.

The activity of ALP in rat serum depended both on the fructan source and the form of their addition to the diet. The highest value of this enzyme was showed in the LC group (104.93); all the animals receiving fructan-enriched diets had a lower ALP activity in the blood serum. OVX-LCJAS rats were characterized by an almost $50 \%$ lower value of this parameter (vs. low-calcium control group). Dietary fructans lowered the osteocalcin level, with significant changes observed between LC-FS and LC, as well as between OVX-LC-YS and OVX-LC groups. Additionally, feeding animals with the diet containing sorbet enriched in yacon or Jerusalem artichoke resulted in decrease $(\mathrm{p} \leq 0.05)$ of CTX, compared to the diet containing yacon or fructan formulation (alone or in the sorbet).

Statistical analysis revealed significant effect of the interactions between the kind and the form of fructan addition to the diet (Tab. 4). The obtained results of the study showed no significant differences in densitometric parameters between treatment groups.

Table 4. Results of two-way analysis of variance ( $p$ values)

\begin{tabular}{lccc}
\hline $\begin{array}{l}\text { Para- } \\
\text { meter }\end{array}$ & $\begin{array}{c}\text { Factor 1 } \\
\text { (kind of fructan source) }\end{array}$ & $\begin{array}{c}\text { Factor 2 } \\
\text { (form of fructan source) }\end{array}$ & $\begin{array}{c}\text { Factor } 1 \times \text { Factor 2 } \\
\text { interaction }\end{array}$ \\
\hline $\mathrm{Ca}^{2+}$ & $\mathrm{ns}$ & 0.003 & $\mathrm{~ns}$ \\
\hline $\mathrm{Mg}$ & $\mathrm{ns}$ & $\mathrm{ns}$ & $\mathrm{ns}$ \\
\hline $\mathrm{P}$ & 0.028 & 0.017 & $\mathrm{~ns}$ \\
\hline $\mathrm{ALP}$ & 0.000 & 0.004 & $\mathrm{~ns}$ \\
\hline $\mathrm{OC}$ & 0.005 & $\mathrm{~ns}$ & $\mathrm{~ns}$ \\
\hline $\mathrm{CTX}$ & 0.043 & $\mathrm{~ns}$ & 0.046 \\
\hline BMC & $\mathrm{ns}$ & $\mathrm{ns}$ & $\mathrm{ns}$ \\
\hline $\mathrm{BMD}$ & $\mathrm{ns}$ & $\mathrm{ns}$ & $\mathrm{ns}$
\end{tabular}

Ns - No statistical significance

ALP - alkaline phosphatase; OC - osteocalcin; CTX - C-telopeptide degradation products from type I collagen; BMC - bone mineral content; BMD - bone mineral density.

\section{DISCUSSION}

An appropriate dietary intake of calcium ( $\mathrm{Ca}$ ), as the principal component of bone, can significantly reduce bone loss and it is crucial to replenish daily Ca losses. When the $\mathrm{Ca}$ intake is insufficient, the organism is forced to increase the process of osteolysis to maintain homeostasis [26]. The obtained results confirmed that Ca dietary restriction $(60 \%$ recommended dose) caused a significant decrease in ionized calcium, phosphorus concentration in serum, as well as the activity of alkaline phosphatase (bone turnover parameter).

It is known that estrogen is a crucial regulator of bone quality and the role of this hormone in human bone health is well-described [6]. A decline in the ovarian production of estrogens at menopause often results in a dramatic loss of bone microarchitecture, increased bone resorption and porosity, all culminating in the development of osteoporosis [22].

The ovariectomized (OVX) rat model is used for studying how potential interventions can preserve bone metabolism in a state that leads to postmenopausal osteoporosis. It is also well-established that an ovariectomy can result in a significant enhancement in bone resorption, a decrease in bone mineral density, as well as deterioration of the bone microarchitecture [27]. The results obtained in the current study show that the ionized calcium concentration in the serum of OVX-LC group were significantly decreased compared with the sham group (SHO-LC). These data were in line with Wang et al. [6], although the authors also observed a markedly lowered phosphorus level. The losses of calcium are also obvious pathological features in osteoporotic patients [9]. There are evidences that fructans can positively impair calcium bioavailability, and improve bone quality $[17,28]$. Positive action of inulin $(10 \%$ in diet, 22 days of treatment) on Ca absorption was reported by Raschka et al. [29]. In turn, increased bone mineralization, density and structure due to an increase in $\mathrm{Ca}, \mathrm{P}$ and $\mathrm{Mg}$ absorptions after the supplementation of Ca-deficient diet with galactooligosaccharides and fructooligosaccharides, was observed by Bryk et al. [30]. As the authors concluded, this prebiotic mixture may help improve bone development in a period of high calcium requirements.

In the presented study, when analyzing the results concerned on ovariectomized rat model after eight weeks of nutritional intervention, no significant changes were observed in ionized calcium (except for OVX-LC-F group) and magnesium concentration in the treatment groups. The increase in phosphorus level in OVX-LC-FS animals was comparable in the OVX-LC, OVX-LC-F, OVX-LC-Y and OVX-LC-JA, as well as the OVX-LC-JAS group.

It should be emphasized that regarding the effects of ovariectomy under calcium dietary restriction, special attention should be paid to bone turnover markers. The results obtained in the current study demonstrate that osteocalcin - bone formation biomarker, significantly increased in the OVX-LC group, compared to the SHO-LC 
group. The same tendency was observed by other authors [6]. Interestingly, feeding female rats with a diet enriched in sorbets containing Beneo Orafti Synergyl and yacon root powder significantly decreased the OC level, compared with the OVX group $(\mathrm{p} \leq 0.05)$.

Moreover, all fructan (independently of the kind and form of addition) led to a significant reduction in ALP activity. These results collectively demonstrate that feeding rats with fructans effectively ameliorates serum biochemical parameters in OVX rats. Similar results were also observed in human studies, after consuming eight $\mathrm{g} /$ day fructooligosaccharides (for three months) by Korean postmenopausal women [31]. Concentration of the CTX, bone resorption biomarker was also significantly increased in the OVX group compared to the sham group. In the current study, the level of this parameter among the treatment groups depended on the kind of fructan ( $\mathrm{p}=0.043)$. This could be explained by the different polymerization degrees of fructans [32]. The interaction between the kind and form of fructan addition was also statistically important $(\mathrm{p}=0.046)$. The OVX-LC-YS and OVXLC-JAS were characterized by the lowest concentration of CTX, with a significant difference observed between this group and OVX-LC-Y, OVX-LC-F and OVX-LC-FS.

When considering the results of statistical analysis it should be mentioned that interactions 'the kind versus the form of fructans' indicate that the matrix of strawberry sorbets could strengthen the beneficial effect of fructan on bone turnover parameters. This is the most apparent in the case of yacon which, when was added as an ingredient of sorbet it was more efficient in decreasing of CTX - bone resorption marker $(\mathrm{p} \leq 0.05)$, than the same component as a raw material (yacon root powder). In the study performed on growing female rats, it was confirmed that strawberry sorbets enriched in fructan sources had more advantageous effects on bone quality than these compounds added to the diet alone [28]

It is known that ovariectomy induces oxidative stress in bone [33]. As an effect of this process, the disturbances in bone remodeling resulting in an unbalance between osteoclast and osteoblast activity, can lead to metabolic bone diseases [34]. On the other hand, fructan as well as strawberries, are regarded as anti-oxidative agents $[21,35$, 36]. There are evidences from clinical studies that reactive oxygen species and/or antioxidant systems can be involved in the pathogenesis of bone loss $[34,37]$. Thus, the effect of a diet containing strawberry sorbets enriched in fructan rather than the raw materials could be derived from other bioactive compounds. To evaluate bone quality in models of osteoporosis several methods and parameters, including measurement of bone density and microarchitecture, as well as its biomechanical properties, are applied [38, 39].

Comparisons with the SHO-LC showed that femoral BMD in the OVX-LC group decreased significantly. Although there were no significant changes after nutritional intervention, an increasing tendency in OVX-LC-FS (vs. OVX-LC) was observed. No differences in BMD between FOS group (5\%, 23 days), compared to control animals, was also observed by Lobo et al. [40]. The same observations were made by Legette et al. [41] in a study on female Sprague-Dawley rats after four-week administration of 5\%inulin or polydextrose. On the contrary, Demigné et al. [42] showed that BMD of diaphysis was improved by chicory treatment (7.5\% inulin) for three months.
The reason for the lack of statistical difference in BMD results in the current study could be the duration of the experiment, which was a limitation of the study. It is possible that longer time of feeding would allow the observation of marked effects of fructan action on bone density. Further long-term studies are planned in this area. It is also emphasized that the results obtained from animal studies could not be to directly extrapolated to the human organism. For that reason, next step should be biological verification of the examined sorbets enriched in fructan sources action in human intervention studies in the context of osteoporosis prevention.

\section{CONCLUSIONS}

The presented study attempted to answer the key question about the relationship between the consequences of dietary calcium restriction combined with estrogen deficiency (caused by ovariectomy) and fructan-enriched diet (including the "matrix effect"). The results obtained suggest that fructan administration has a positive effect on bone turnover parameters (OC, ALP). Feeding rats a diet containing yaconenriched sorbet, as well as Jerusalem artichoke-enriched sorbet, significantly affected the CTX concentration in serum of OVX rats. It is possible that other constituents of strawberry sorbets contributed to their effects on the bone turnover parameters. The kind of fructan source (raw material or sorbet) significantly affected the phosphorus level and alkaline phosphatase activity in rat serum. Moreover, CTX serum level was the only parameter where a significant interaction between the kind of fructan source and the form of its addition to the diet was observed.

\section{Conflict of interest}

The authors declare that they have no conflict of interest.

\section{Acknowledgements}

The study was founded by the National Science Centre Poland project, on the basis of Decision No. DEC-2011/01/B/ NZ9/03045.

\section{REFERENCES}

1. Feng X, McDonald JM. Disorders of Bone Remodeling. Annu Rev Pathol. 2011; 6: 121-145.

2. El Khassawna T, Böcker W, Govindarajan P, Schliefke N, Hürter B, Kampschulte M., Schlewitz G, Alt V, Lips KS, Faulenbach M., Möllmann H, Zahner D, Dürselen L, Ignatius A, Bauer N, Wenisch S, Langheinrich AC, Schnettler R, Heiss C. Effects of multi-deficiencies-diet on bone parameters of peripheral bone in ovariectomized mature rat. PloS ONE. 2013; 8(8): e71665.

3. World Health Organization. Assessment of Osteoporosis at the Primary Health Care Level. Report of a WHO Scientific Group. Geneva: WHO 2007.

4. Bonjour JP, Kohrt W, Levasseur R, Warren M, Whiting S, Kraenzlin $\mathrm{M}$. Biochemical markers for assessment of calcium economy and bone metabolism: application in clinical trials from pharmaceutical agents to nutritional products. Nutr Res Rev. 2014; 27(2): 252-67.

5. Tu M-Y, Chen H-L, Tung Y-T, Kao C-C, Hu F-C, Chen C-M ShortTerm Effects of Kefir-Fermented Milk Consumption on Bone Mineral Density and Bone Metabolism in a Randomized Clinical Trial of Osteoporotic Patients. PLoS ONE. 2015; 10(12): e0144231. doi:10.1371/ journal.pone.014423

6. Wang Q, Zi C-T, Wang J, Wang Y-N, Huang Y-W, Fu X-Q, Wang X-J and Sheng J. Dendrobium officinale Orchid Extract Prevents Ovariectomy- 
Induced Osteoporosis in Vivo and Inhibits RANKL-Induced Osteoclast Differentiation in Vitro. Front Pharmacol. 2018; 8: 966.

7. Liu T, Ding S, Yin D, Cuan X, Xie C, Xu H, Wang X, Sheng J. Pu-erh tea extract ameliorates ovariectomy-induced osteoporosis in rats and suppresses osteoclastogenesis in vitro. Front Pharmacol. 2017; 8: 324.

8. Price CT, Langford JR, Liporace FA. Essential Nutrients for Bone Health and a Review of their Availability in the Average North American Diet. The Open Orthopaed J. 2012; 6: 143-149.

9. Curtis EM, Moon RJ, Dennison EM, Harvey NC, Cooper C. Recent advances in the pathogenesis and treatment of osteoporosis. Clin Med. 2016; 16: 360-364.

10. Whisner CM, Castillo LF. Prebiotics, Bone and Mineral Metabolism Calcif Tissue Int. 2018; 102: 443.

11. Sabater-Molina M, Larque' E, Torrella F, Zamora S. Dietary fructooligosaccharides and potential benefits on health. J Physiol Biochem. 2009; 65: 315-328.

12. Kolida S, Gibson GR. Prebiotic Capacity of Inulin-Type Fructans J Nutr. 2007; 137,11:1. Pages 2503S-2506S. https://doi.org/10.1093/ jn/137.11.2503S.

13. Franco-Robles E, López MG. Implication of Fructans in Health: Immunomodulatory and Antioxidant Mechanisms. Sci World J. 2015 Article ID 289267, 15 pages, http://dx.doi.org/10.1155/2015/289267.

14. Roberfroid MB. Inulin-type fructans: functional food ingredients. J Nutr. 2007; 137: 2493S-2502S.

15. Roberfroid M, Gibson GR, Hoyles L, McCartney AL, Rastall R, Rowland I, Wolvers D, Watzl B, Szajewska H, Stahl B, Guarner F, Respondek F, Whelan K, Coxam V, Davicco MJ, Léotoing L, Wittrant Y, Delzenne NM, Cani PD, Neyrinck AM, Meheust A.Prebiotic effects: metabolic and health benefits. Br J Nutr. 2010; 104(Suppl): S1-S63.

16. Topolska K, Filipiak-Florkiewicz A, Florkiewicz A, Cieślik E. Fructan stability in strawberry sorbets in dependence on their source and the period of storage. Eur Food Res Technol. 2017; 243: 701-709.

17. Cieślik E, Topolska K, Pisulewski PM. Effect of inulin-type fructans on body weight gain and selected biochemical parameters at calcium hypoalimentation in rats. Pol J Food Nutr Sci. 2009; 59(2): 163-168.

18. Cieślik E, Florkiewicz A, Filipiak-Florkiewicz A. [Quality of fruit juices with fructans additions]. Żyw Człow Metab. 2003; 3: 1027-1030. Polish.

19. Praznik W, Cieślik E, Filipiak-Florkiewicz A. Soluble dietary fibres in Jerusalem artichoke powders: composition and application in bread. Nahrung 2002; 46(3): 151-157.

20. Żary-Sikorska E, Juśkiewicz J. Effect of fructans with different degrees of polymerization on bacterial enzymes activity, lipid profile and antioxidant status in rats. Pol J Food Nutr Sci. 2008; 58(2): 269-272.

21. Domazetovic V, Marcucci G, Iantomasi T, Brandi ML, Vincenzini MT. Oxidative stress in bone remodeling: role of antioxidants Clin Cases Miner Bone Metab. 2017; 14(2): 209-216.

22. Johnston BD, Ward WE. The Ovariectomized Rat as a Model for Studying Alveolar Bone Loss in Postmenopausal Women. BioMed Res Int. 2015; Article ID 635023, 12 pages, http://dx.doi.org/10.1155/2015/635023.

23. French DL, Muir JM, Webber CE. The ovariectomized, mature rat model of postmenopausal osteoporosis: an assessment of the bone sparing effects of curcumin. Phytomed. 2008; 15: 1069-1078.

24. Yamauchi H, Kushida K, Yamazaki K, Inoue T. Assessment of spine bone mineral density in ovariectomized rats using DXA. J Bone Miner Res. 1995; 10: 1033-1039.

25. Reeves PG, Nielsen FH, Fahey GC Jr. AIN-93 purified diets for laboratory rodents: final report of the American Institute of Nutrition ad hoc writing committee on the reformulation of the AIN-76A rodent diet. J Nutr. 1993; 123(11): 1939-1951.
26. Karpouzos A, Diamantis E, Farmaki P, Savvanis S, Troupis T. Nutritional Aspects of Bone Health and Fracture Healing, J Osteoporos. 2017; Article ID 4218472, 10 pages, https://doi.org/10.1155/2017/4218472.

27. Ye Q, Ma XQ, Hu CL, Lin B, Xu LS, Zheng CJ, Qin LP. Antiosteoporotic activity and constituents of Podocarpium podocarpum. Phytomed. 2015; 22: 94-102. doi:10.1016/j.phymed.2014.11.004.

28. Topolska K, Radzki RP, Filipiak-Florkiewicz A. Florkiewicz A., Leszczyńska T., Cieślik E. Fructan-Enriched Diet Increases Bone Quality in Female Growing Rats at Calcium Deficiency. Plant Foods Hum Nutr. 2018; 73(3): 172-179.

29. Raschka L, Daniel H. Mechanisms underlying the effects of inulin-type fructans on calcium absorption in the large intestine of rats. Bone. 2005; 37: 728-735.

30. Bryk G, Coronel MZ, Pellegrini G, Mandalunis P, Rio ME, de Portela ML, Zeni SN. Effect of a combination GOS/FOS ${ }^{\star}$ prebiotic mixture and interaction with calcium intake on mineral absorption and bone parameters in growing rats. Eur J Nutr 2015; 54: 913-923.

31. Kim YY, Jang KH, Lee EY. Cho Y, Kang SA, Ha WK, Choue R. The effect of chicory fructan fiber on calcium absorption and bone metabolism in Korean postmenopausal women. Nutr Sci. 2004; 7(3): 151-157.

32. Scholz-Ahrens KE, Schrezenmeir J. Inulin and oligofructose and mineral metabolism: the evidence from animal trials. J Nutr. 2007; 137(11 Suppl): 2513S-2523S.

33. Muthusami S, Ramachandran I, Muthusamy B, Vasudevan G, Prabhu V, Subramaniam V, Jagadeesan A, Narasimhan S. Ovariectomy induces oxidative stress and impairs bone antioxidant system in adult rats. Clin Chim Acta. 2005; 360: 81-86.

34. Baek KH, Oh KW, Lee WY, Lee SS, Kim MK, Kwon HS, Rhee EJ, Han JH, Song KH, Cha BY, Lee KW, Kang MI. Association of oxidative stress with postmenopausal osteoporosis and the effects of hydrogen peroxide on osteoclast formation in human bone marrow cell cultures. Calcif Tissue Int. 2010; 87: 226-235.

35. Pasqualetti V, Altomar, A, Guarino MPL, Locato V, Cocca S, Cimini S, Palma R, Alloni RAND De Gara L, Cicala M. Antioxidant Activity of Inulin and Its Role in the Prevention of Human Colonic Muscle Cell Impairment Induced by Lipopolysaccharide Mucosal Exposure, PLOS ONE. 2014; 9(5): e98031. https://doi.org/10.1371/journal.pone.0098031.

36. Giampieri F, Tulipani S, Alvarez-Suarez JM, Quiles JL, Mezzetti B, Battino $\mathrm{M}$. The strawberry: composition, nutritional quality, and impact on human health. Nutrition. 2012; 28(1): 9-19 doi: 10.1016/j. nut.2011.08.009.

37. Ostman B, Michaelsson K, Helmersson J, Byberg L, Gedeborg R, Melhus $\mathrm{H}, \mathrm{Basu}$ S. Oxidative stress and bone mineral density in elderly men: antioxidant activity of alpha-tocopherol. Free Radic Biol Med. 2009; 47: 668-673.

38. Kuo TR, Chen CH. Bone biomarker for the clinical assessment of osteoporosis: recent developments and future perspectives. Biomarker Res. 2017, 5: 18.

39. Liu T, Ding S, Yin D, Cuan X, Xie C, Xu H, Wang X, Sheng J. Pu-erh tea extract ameliorates ovariectomy-induced osteoporosis in rats and suppresses osteoclastogenesis in vitro. Front Pharmacol. 2018, 8: 324.

40. Lobo AR, Colli C, Filisetti T. Fructooligosaccharides improve bone mass and biomechanical properties in rats. Nutr Res. 2006; 26: 413-420.

41. Legette LL, Lee W, Martin BR, Story JA, Cambell JA, Weaver CM. Prebiotics enhance magnesium absorption and inulin-based fibers exert chronic effects on calcium utilization in a postmenopausal rodent model. J Food Sci. 2012; 77: H88-H94.

42. Demigné C, Jacobs H, Moundras C, Davicco MJ, Horcajada MN, Bernalier A, Coxam V. Comparison of native or reformulated chicory fructans, or non-purified chicory, on rat cecal fermentation and mineral metabolism. Eur J Nutr. 2008; 47(7): 366-374. 